\title{
Toros göknarı için uyumlu hacim ve gövde çapı modelleri
}

\author{
Onur Alkan a,* (i), Ramazan Özçelika (iD
}

\begin{abstract}
Özet: Bu çalışmada, orman envanteri uygulamaları için bir gövde çapı modelinin seçiminde kullanılabilecek istatistiksel ve pratik hususları göstermek amacıyla Toros göknarı (Abies cilicica Carr.) için dört gövde çapı modeli karşılaştırmalı olarak değerlendirilmiştir. Bu amaçla Kozak vd. (1969), Demaerschalk (1972), Max ve Burkhart (1976) ve Clark vd. (1991) tarafindan geliştirilen uyumlu gövde çapı modelleri seçilmiştir. Modeller, ortalama hata (MD), tahminlerin standart hatası (SEE) ve uyum indeksi (FI) ölçüt değerleri kullanılarak karşılaştırılmıştır. Çalışma sonucunda, Clark vd. (1991) tarafindan geliştirilen modelin gövde çapı ve gövde hacmi tahminlerinde diğer modellerden daha üstün olduğu görülmüştür. Ancak bu model gövde çapı ve hacim tahminleri için 5.30 m'deki çap değerine de ihtiyaç duyması nedeniyle Max ve Burkhart (1976) modelinin test edilen modeller arasında pratik ormancılık uygulamaları için daha uygun olduğu sonucuna varılmıştır. Clark vd. (1991), Max ve Burkhart (1976) ve Demaerschalk (1972) modelleri çap ve hacim tahminlerindeki MD ve SEE değerleri bakımından hem tüm gövde hem de gövdenin farklı bölümleri için tutarlı tahmin performansları göstermiş̧ir. Test edilen modeller için çap tahminlerindeki ortalama hata $2.0 \mathrm{~cm}$ 'den, hacim tahminlerindeki ortalama hata ise $0.01 \mathrm{~m}^{3}$ 'ten daha azdır. Karșlaștırılan tüm modeller, 10 farklı nispi boy sınıfı esas alındığında, herhangi bir noktadaki çap ve ticari gövde hacim tahminleri için güvenilir sonuçlar üretmiştir.
\end{abstract}

Anahtar sözcükler: Uyumlu gövde çapı modeli, Gövde çapı ve hacim, Toros göknarı

\section{Compatible stem volume and taper equations for Cilicica fir}

\begin{abstract}
Four taper estimating systems were evaluated for Cilicica fir (Abies cilicica Carr.) in Turkey to demonstrate statistical and practical considerations that should be used when selecting a taper estimating system for forest inventory purposes. The four equations selected were: Kozak et al. (1969), Demaerschalk (1972), Max and Burkhart (1976), and Clark et al. (1991). Tested models have been compared using evaluation statistics like as: mean difference (MD), standard error of the estimate (SEE), and Fit index (FI). Clark et al. (1991)'s segmented taper model was superior in predicting Cilicica fir stem form and stem volume than the other models. However, since this model also requires the measurement of the upper stem diameter value at $5.30 \mathrm{~m}$ for stem diameter and volume estimations, it was concluded that Max and Burkhart (1976) model is more suitable for practical forestry purposes among the models tested. Clark et al.'s, Max and Burkhart's, and Demaerschalk's models showed consistent prediction performances for both the whole stem and different parts of the stem in terms of MD and SEE values in diameter and volume estimates. Average diameter and volume prediction errors were less than $2.0 \mathrm{~cm}$ and $0.01 \mathrm{~m}^{3}$, respectively. All models produced reliable results for diameter and merchantable taper volume estimates at any point, based on 10 different relative height classes.
\end{abstract}

Keywords: Compatible stem diameter model, Taper and volume, Abies cilicica

\section{Giriş}

Ağaç gövde hacim tahminleri, orman envanteri ve planlama çalışmalarının en önemli aşamalarından birisini oluşturmaktadır. Uzun yıllardır Türkiye'de ağaç türlerine ilişkin gövde hacim tahminlerinde, yöresel tek girişli hacim tabloları kullanılmaktadır. Ancak değişen pazar şartları ve farklı faydalanma alternatifleri için doğru hacim tahminlerine olan ihtiyacın karşılanması konusunda günümüzde kullanılan yöresel hacim tabloları yetersiz kalmaktadır. Son yıllarda, herhangi bir ticari standart için gövde hacmini ya da herhangi bir noktadaki gövde çapını tahmin etmek için en doğru yaklaşımlardan birisinin, uyumlu hacim ve gövde çapı modelleri olduğu ifade edilmektedir (Jiang vd. 2005; Özçelik ve Alkan, 2012; Özçelik ve Crecente-Campo, 2016; Alkan vd., 2019). Bir gövde çapı denkleminin dip kütük ile tepe noktası arasındaki integrali alındığında, elde edilen hacim toplam gövde hacmine; dip kütük ile gövdenin belirli yükseklikleri arası için integrali alındığında elde edilen hacim, hacim oran denklemi ile hesaplanan hacme eşit ise böyle denklemler "uyumlu gövde çapı denklemi" olarak isimlendirilmektedir (Demaerschalk, 1972). Ülkemizdeki pek çok ağaç türü için özelikle yöresel düzeyde geliştirilmiş uyumlu gövde çapı ve hacim modeli bulunmamaktadır.

Kozak (2004)'e göre, gövde çapı modelleri; (1) gövde boyunca herhangi bir noktadaki çap değerinin, (2) toplam gövde hacminin, (3) dipten gövde üzerindeki herhangi bir uç çap değeri için ticari boyun ve ticari hacmin ve (4) dipten herhangi bir yükseklikteki ve boydaki tomruk hacimlerinin tahminine imkân sağlamaktadır. Yüz yılı aşkın bir süredir gövde formunun modellenmesi amacıyla değişik formda pek çok gövde çap1 modeli geliştirilmiştir (McTague ve Weiskittel, 2021). Bununla birlikte, pek çok araştırıcı

\footnotetext{
$凶$ a Isparta Uygulamalı Bilimler Üniversitesi, Orman Fakültesi, 32260, Isparta

@ * Corresponding author (İletişim yazarı): onuralkan@isparta.edu.tr

$\checkmark \quad$ Received (Geliş tarihi): 01.09.2021, Accepted (Kabul tarihi): 23.09.2021
}

Citation (Atıf): Alkan, O., Özçelik, R., 2021. Toros göknarı için uyumlu hacim ve gövde çapı modelleri. Turkish Journal of Forestry, 22(4): 408-416. DOI: $\underline{10.18182 / \text { tjf. } 989732}$ 
tarafından bu konuda farklı ağaç türleri ve yetişme ortamları için daha fazla çalışmanın yapılmasının gerekli olduğu da vurgulanmıştır (Sharma ve Parton 2009; Eker vd., 2017; Jiang vd., 2005). Newnham (1988)'e göre, bu alanda yeni çalışmaların yapılması gerektiğinin iki önemli nedeni bulunmaktadır. Bunlardan ilki, farklı ağaç türleri için gövde formlarındaki varyasyonu tanımlamaya yetecek tek bir teorinin geliştirilememiş olmasıdır. İkincisi ve ormancılık uygulamaları açısından daha da önemlisi, sürekli değişen pazar koşullarına bağlı olarak değişen odun çeşidi standartlarını dikkate alan bir yöntemin elde edilememiş olmasıdır.

Geçen yüzyıl boyunca farklı formlarda basit gövde çapı modellerinden (Kozak vd., 1969; Demaerschalk, 1972; Ormerod, 1973; Hilt, 1980; Biging, 1984; McTague ve Bailey, 1987; Thomas ve Parresol, 1991; Sharma ve Oderwald, 2001; Zakrzewski ve MacFarlane, 2006) karmaşık gövde çapı modellerine kadar (Max ve Burkhart, 1976; Demaerschalk ve Kozak, 1977; Cao vd., 1980; Clark vd., 1991; Kozak 1988 ve 2004; Bi, 2000; Fang vd., 2000; Jiang vd., 2005; Jordan vd., 2005) pek çok model geliştirilmiştir. Basit gövde çapı modelleri, ağaçların genel gövde formunu tek bir model ile tanımlamada genel olarak yeterliyken, tüm gövdeyi tanımlamada yetersiz kalmaktadır. $\mathrm{Bu}$ tip gövde çapı modelleri, gövdenin orta bölümünü nispeten başarılı bir şekilde tanımlarken, dip ve üst gövde bölümlerini tanımlamada yetersiz kalmaktadır (Max ve Burkhart 1976; Demaerschalk ve Kozak 1977; Kozak 1988; Newnham 1992). Basit gövde çapı modellerinin bu dezavantajları, ilk örneği Max ve Burkhart (1976) tarafindan tanıtılan parçalı gövde çapı modelleri ile giderilmeye çalışılmıştır. Bu model formunda, gövde üç parçaya ayrılmış ve her bir gövde parçası farklı fonksiyonlar yardımı ile tanımlanmıştır. Birçok araştırmacı, bu yaklaşım tarzını farkl1 ağaç türlerinin gövde çap1 ve gövde hacim tahminlerinde başarı ile kullanmışlardır (Coble ve Hilpp, 2006; Brooks vd., 2008; Shahzad vd., 2021).

Özellikle son yirmi yılda yapılan çalışmalarda, değişik formdaki gövde çapı modellerinin; gövde çapı, ticari hacim ve toplam hacim tahminlerindeki performansı karşılaştırılmıştır. Örneğin Martin (1981) tarafından yapılan bir çalışmada, bazı gövde çapı modelleri karşılaştırılmış ve çap, boy ve hacim tahminleri için tek bir model formunun en başarılı model olmamasına rağmen, Max ve Burkhart (1976) tarafindan geliştirilen modelin genel olarak daha başarılı olduğu görülmüştür. Cao vd. (1980), gövde çapı tahminleri amacıyla altı farklı modeli karşılaştırmış ve Max ve Burkhart (1976) parçalı gövde çapı modelini daha başarılı bulmuştur. Figueiredo-Filho vd. (1996) ise beş farklı gövde çapı modelini çap, ticari hacim ve toplam hacim tahminleri açısından dört farklı ölçüt değeri kullanılarak değerlendirmiştir. Bu çalışmada kullanılan değerlendirme istatistiklerinin pek çoğuna göre, Clark vd. (1991) gövde çap1 modelinin, gövde profilinin modellenmesi ve gövde hacim tahminleri açısından diğer modellerden daha başarılı olduğu görülmüştür. Kozak ve Smith (1993), orman envanteri amaçları açısından dört farklı gövde çapı modelini karşılaştırmıştır. Sonuçlar, Kozak (1988) modelinin Ormerod (1986), Max ve Burkhart (1976) ve Newnham (1988)'den çap ve toplam hacim tahminleri açısından daha başarılı olduğunu ortaya koymuştur. Özçelik ve CrecenteCampo (2016) tarafından yapılan çalışmada ise, değişik formlarda (basit, parçalı ve değişken şekil) on farklı model, çap, toplam hacim, ticari hacim ve ticari boy tahminleri açısından karşılaştırılmış ve Clark vd. (1991) tarafindan geliştirilen modelin diğer modellere göre daha başarılı olduğu görülmüştür. Aynı çalışmada, genel olarak parçalı gövde çap1 modellerinin, diğer formlardaki gövde çapı modellerine göre daha iyi tahmin performansı gösterdiği de görülmüştür. Hussain vd. (2020) tarafindan üç farklı ağaç türü için beş farklı model; gövde çapı, ticari hacim ve toplam hacim tahminlerindeki başarı durumları açısından karşılaştırılmış ve en başarılı sonuçlar Clark vd. (1991) ile elde edilmiştir. Shahzad vd. (2020) tarafindan yapılan çalışmada, farklı formlardaki sekiz gövde çapı modeli; çap, ticari ve toplam hacim tahminleri açısından karşılaştırılmış ve kullanılan değerlendirme ölçütleri açısından Fang vd. (2000) tarafindan geliştirilen gövde çapı modelinin en başarılı sonuçları verdiği görülmüştür. Hussain vd. (2021) ise iki farklı ağaç türü için farklı formlardaki sekiz gövde çap1 modelini; gövde çapı, ticari ve toplam hacim tahminlerindeki başarılı durumları açısından karşılaştırmış ve en başarılı sonuçların Clark vd. (1991) ile elde edildiğini belirlemişlerdir. Shahzad vd. (2021) tarafindan yapılan diğer bir çalışmada ise, üç farklı gövde çapı modeli, gövde çap1 tahminlerindeki başarısı açısından karşılaştırılmış ve en başarılı sonuçlar Max ve Burkhart (1976) modeli ile elde edilmiştir. Tüm bu çalışmaların ortak bir sonucu olarak, parçalı gövde çapı modellerinin diğer gövde çapı modellerine göre daha başarılı oldukları ve özellikle Clark vd. (1991) ve Max ve Burkhart (1976) tarafindan geliştirilen parçalı gövde çapı modellerinin diğer modellere oranla daha yüksek tahmin performansına sahip olduğu söylenebilir. Ülkemizde değişen piyasa şartlarına bağlı olarak orman ürünleri endüstrisindeki talepleri karşılamak amacıyla, farklı ağaç türleri ve yöreler için gövde çapı ve gövde hacim tahminlerinde kullanılabilecek uyumlu gövde çapı modellerine ihtiyaç duyulmaktadır. Bununla birlikte, seçilecek modelin hem rutin orman envanteri çalışmalarında kolayca kullanılabilmesi hem de elde edilen sonuçların istatistiki açıdan tatmin edici olması gereklidir.

Kozak ve Smith (1993) tarafından yapılan bir çalışmada, değişik formlardaki dört farklı gövde çapı modeli pratik ormancılık uygulamaları açısından istatistiki ölçütlerle değerlendirilmiştir. Bu kapsamda, bir gövde çapı modelinin pratik ormancılık uygulamaları açısından;

- Değişik ticari standartlara sahip odun hacmini doğru tahmin edebilmesi,

- Model katsayılarının kolayca tahmin edilebilmesi,

- Denklemin kolay uygulanabilir olması,

- Ticari ve toplam hacim tahminleri için kolayca hacim denklemine dönüştürülebilir olması,

- Denklem için gerekli olan bağımsız değişkenlerin (çap, boy vb.) kolay ölçülebilir olması

- Modelin ilgili ağaç türü için geniş bir coğrafi bölgede test edilmiş olması gibi özelliklere sahip olması gerekmektedir.

Model performanslarının değerlendirilmesinde kullanılacak istatistiki değerlendirme ölçütleri açısından ise;

- MD, SEE ve FI gibi ölçütlerin birlikte kullanılması gerektiği,

- Bunun mümkün olmadığı ya da tek bir ölçütün kullanılacağı durumlarda ise FI'nin kullanılmasının yararlı olacağını belirtilmiştir. 
$\mathrm{Bu}$ çalışma kapsamında dört farklı uyumlu gövde çapı modeli, tüm ağaç ve on farklı nispi boy sınıfı için yukarıda belirtilen pratik ormancılık uygulamaları ve farklı tahmin performans ölçütleri kullanılarak değerlendirilmiştir. Bu amaçla, Türkiye'nin en önemli asli ağaç türlerinden birisi olan Toros göknarı meşcerelerinden alınan örnek ağaç verileri kullanılmıştır. Toros göknarı ormanları ülkemizde yaklaşı $279,020.6$ ha alan kaplamakta ve bu alan üzerinde yaklaşık 41,7 milyon $\mathrm{m}^{3}$ ağaç serveti bulundurmaktadır (OGM, 2006). Toros göknarı, Türkiye'de orman ürünleri endüstrisinde; ambalaj, mobilya, kâğıt hamuru ve kâğıt ve kalıp yapımı vb. alanlarda yoğun olarak kullanılmaktadır. $\mathrm{Bu}$ nedenle, Toros göknarı meşcerelerinin sürdürülebilir yönetim ilkeleri ve odununun kullanım alanları incelendiğinde, çok yönlü ve doğru hacim tahmin yöntemlerine ihtiyaç duyulduğu anlaşılmaktadır.

\section{Materyal ve yöntem}

\subsection{Materyal}

Bu çalışmada kullanılan toplam 204 örnek ağaç verisi eşit yaşlı ve doğal Toros göknarı meşcerelerinden elde edilmiştir. Örnek ağaçlar, Bucak Orman İşletme Müdürlüğündeki doğal Toros göknarı meşcerelerinin yayılış gösterdiği alanlar boyunca, mümkün olduğunca farklı çap ve boy sınıflarından homojen bir dağılışla toplanmıştır. Her örnek ağaç üzerinde göğüs çapı dijital çap ölçer yardımı ile $0.1 \mathrm{~cm}$ hassasiyetle ölçülmüştür. Örnek ağaçlar yaklaşı 0.3 $\mathrm{m}$ yükseklikten kesildikten sonra, $0.05 \mathrm{~m}$ hassasiyetle önce ağaç boyları şerit metre yardımı ile ölçülmüş; ardından 0.3 m'den başlanarak 1'er metre aralıklarla ağaç gövdesi boyunca tepe tomurcuğuna kadar çap ölçümleri gerçekleştirilmiştir. Her ölçüm noktasında, birbirine dik iki çap ölçümü gerçekleştirilmiş ve ortalaması alınmıştır. Her ağaçta, gövde bölümünün hacmi Bailey (1995) tarafından geliştirilen "overlapping bolt method" yöntemi kullanılarak tahmin edilmiştir. Örnek ağaçların seçiminde, çalışma alanındaki genel meşcere koşullarının (sıklık, gelişme çağı, vb.) ve farklı çap-boy kademelerinin en iyi şekilde temsil edilebilmesine özen gösterilmiştir. Ölçümü yapılan 204 örnek ağaç, tesadüfi olarak model geliştirmek ve geliştirilen modellerin test edilmesi amacıyla iki gruba ayrılmıştır. $\mathrm{Bu}$ amaçla örnek ağaçların \%75'i $(n=150)$ model parametrelerinin tahmini amacıyla; geri kalan yaklaşık $\% 25$ 'i $(\mathrm{n}=54)$ ise geliştirilen modellerin gövde çapı ve toplam hacim tahminlerindeki performanslarının tahmini amacıyla kullanılmıştır. Her iki veri grubuna ilişkin tanımlayıcı istatistikler Çizelge 1 ve Çizelge 2'de verilmiştir. Şekil 1'de ise, her iki veri grubuna ilişkin nispi çap değerlerine karşılık gelen nispi boy değerlerini gösteren grafik verilmiştir.
Çizelge 1. Model geliştirme verileri için nitelendirici istatistikler

\begin{tabular}{lrrrc}
\hline & Ortalama & $\begin{array}{c}\text { Standart } \\
\text { sapma }\end{array}$ & Minimum & Maksimum \\
\hline $\begin{array}{l}\text { Toros göknarı } \\
(n=150)\end{array}$ & & & & \\
$\begin{array}{l}\text { Göğ̈̈s çapı } \\
(D, c m)\end{array}$ & 34.50 & 12.35 & 14.00 & 70.00 \\
$\begin{array}{l}\text { Toplam boy } \\
(H, m)\end{array}$ & 15.82 & 4.36 & 7.60 & 27.30 \\
$\begin{array}{l}\text { Disk kabuklu çap1 } \\
(d, c m)\end{array}$ & 20.44 & 19.24 & 1.00 & 74.00 \\
$\begin{array}{l}\text { Disk boyu } \\
(h, m)\end{array}$ & 8.35 & 5.52 & 0.30 & 26.30 \\
\hline
\end{tabular}

Çizelge 2. Model test verileri için nitelendirici istatistikler

\begin{tabular}{lcccc}
\hline & Ortalama & $\begin{array}{c}\text { Standart } \\
\text { sapma }\end{array}$ & Minimum & Maksimum \\
\hline $\begin{array}{l}\text { Toros göknarı } \\
(n=54)\end{array}$ & & & & \\
$\begin{array}{l}\text { Göğ̈̈s çap1 } \\
(D, c m)\end{array}$ & 36.83 & 14.63 & 15.00 & 73.00 \\
$\begin{array}{l}\text { Toplam boy } \\
(H, m)\end{array}$ & 16.27 & 5.05 & 8.00 & 26.00 \\
$\begin{array}{l}\text { Disk kabuklu çap1 } \\
(d, c m)\end{array}$ & 21.74 & 21.00 & 1.00 & 76.00 \\
$\begin{array}{l}\text { Disk boyu } \\
(h, m)\end{array}$ & 8.74 & 5.85 & 0.30 & 25.30 \\
\hline
\end{tabular}

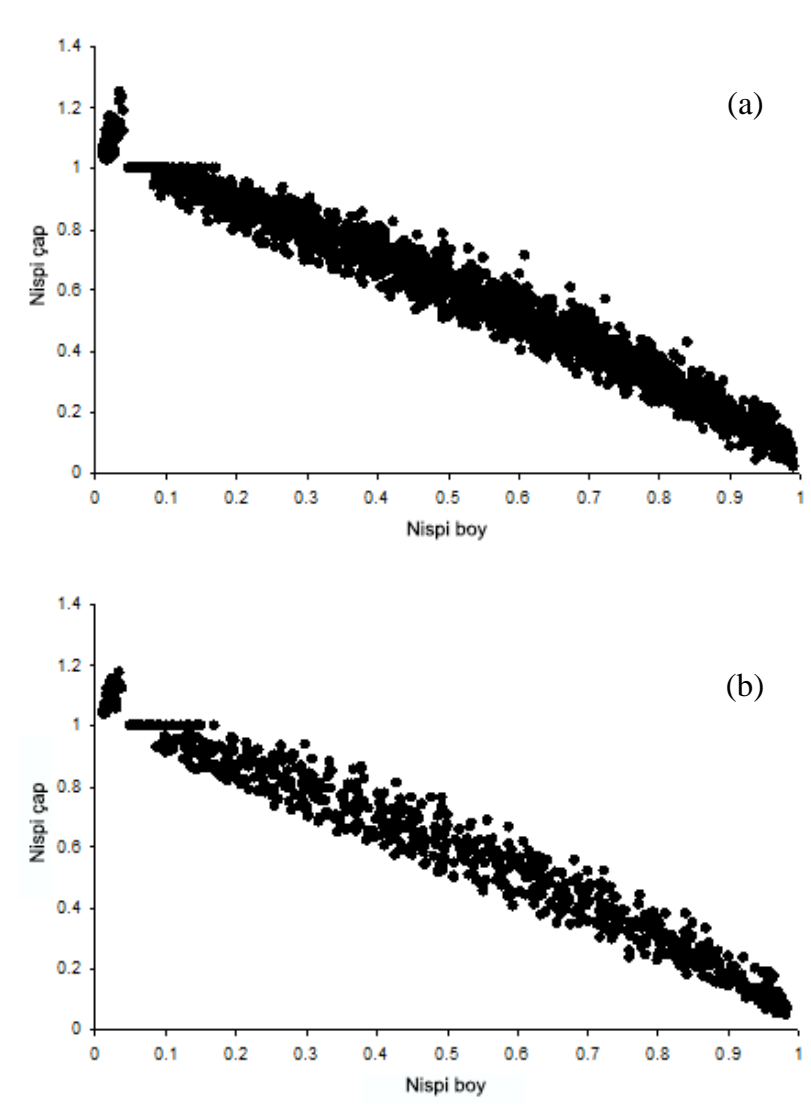

Şekil 1. Model geliştirme (a) ve model test (b) verileri için nispi çap-nispi boy grafiği 


\subsection{Yöntem}

\section{Gövde çapı ve hacim denklemleri}

$\mathrm{Bu}$ çalışma için dört farklı uyumlu gövde çapı modeli seçilmiştir. Bu modellerden ikisi basit gövde çapı modeli (Kozak vd., 1969 ve Demaerschalk, 1972) iken, diğer ikisi parçalı gövde çap1 modelidir (Max ve Burkhart, 1976 ve Clark vd., 1991). Yapılan çalışmalar, parçalı gövde çap1 modellerinin, diğer gövde çapı modellerine göre gövde formunu tanımlamada daha başarılı olduğunu göstermiştir. Bu çalışmada kullanılan Max ve Burkhart (1976) ve Clark vd. (1991) parçalı gövde çapı modelleri, son yıllarda değişik ağaç türleri için çap ve hacim tahminleri amaciyla en çok test edilen ve çoğunlukla da en başarılı sonuçları üreten modeller olarak karşımıza çıkmaktadır (Cao vd., 1980; Martin, 1981; Figueiredo-Filho vd., 1996; Özçelik ve Crecente-Campo, 2016; Shahzad vd., 2020).

Model 1: Kozak vd. (1969) tarafindan önerilen uyumlu hacim ve gövde çapı modeli:

$d=\left[D^{2}\left(b_{1}\left(\frac{h}{H}-1\right)+b_{2}\left(\frac{h^{2}}{H^{2}}-1\right)\right)\right]^{0.5}+\varepsilon$

$V=0.0000785 * D^{2}\left[\frac{b_{1}\left(h_{u}^{2}-h_{l}^{2}\right)}{2 H}+\frac{b_{2}\left(h_{u}^{3}-h_{l}^{3}\right)}{3 H^{2}}-\left(b_{1}+b_{2}\right)\left(h_{u}-\right.\right.$

$\left.\left.h_{l}\right)\right]+\varepsilon$

Burada, $H$, toplam ağaç boyu (m); $D$, kabuklu göğüs çapı $(\mathrm{cm}) ; V$, toplam kabuklu gövde hacmini $\left(\mathrm{m}^{3}\right) ; d$, ağaç gövdesi üzerinde değişik noktalarda ölçülen çap değerlerini $(\mathrm{cm}) ; h, d$ çapının ölçüldüğü yüksekliği $(\mathrm{m}) ; h_{u}$, gövde bölümünün üst noktasını; $h_{l}$, gövde bölümünün alt noktasını; $z$, oransal boyu $(h / H)$ ve $b_{i}$ ise denklem katsayılarını ifade etmektedir.

Model 2: Demaerschalk (1972) tarafindan, mevcut hacim denklemlerinin uyumlu gövde çapı denklemlerine kolayca dönüştürülebileceği yeni bir yaklaşım sunulmuştur. $\mathrm{Bu}$ yöntemde, gövde çapı denklemi, mevcut bir logaritmik hacim denkleminden elde edilmektedir.

$$
\begin{aligned}
& d=\left[D^{2}\left(\left(10^{2 b_{1}}\right) *\left(D^{2 b_{2}}-2\right) *\left[(H-h)^{2 b_{3}}\right] *\left(H^{2 b_{4}}\right)\right)\right]^{0.5} \\
& V=\frac{(0.0000785) *\left(10^{2 b_{1}}\right) *\left(D^{2 b_{2}}\right) *\left(H^{2 b_{4}}\right) *\left(X_{1}^{Z}-X_{2}^{Z}\right)}{Z}
\end{aligned}
$$

Burada,

$$
Z=\left(2 b_{2}\right)+1 ; X_{l}=H-h_{l} ; X_{2}=H-h u \text { 'yi ifade etmektedir. }
$$

Model 3: Max ve Burkhart (1976) parçalı gövde çap1 modeli:

Üç farklı denklemden oluşan bu model, gövdenin en alt kısmının neiloid, orta bölümünün kesik paraboloid, en üst bölümünün ise koni şeklinde olduğu varsayımından hareket etmektedir. Bu üç farklı denklem, iki ayrı katılma noktası ile birleştirilerek, tek bir denklem haline getirilmektedir. Model formu aşağıdaki gibi ifade edilebilir.

$$
\begin{aligned}
& \frac{d^{2}}{D^{2}}=b_{1}(Z-1)+b_{2}\left(Z^{2}-1\right)+b_{3}\left(a_{1}-Z\right)^{2} I_{1}+ \\
& b_{4}\left(a_{2}-Z\right)^{2} I_{2}
\end{aligned}
$$

Burada,

$I_{i}=\left\{\begin{array}{ll}1 & Z \leq a_{i} \\ 0 & Z>a_{i}\end{array} \quad i=1,2\right.$

$a_{i}=$ örnek veriler ile hesaplanan katılım noktaları. $i=$ 1,2 ,

$V=K D^{2} H\left\{\begin{array}{l}\frac{b_{2}}{3}\left(Z_{u}^{3}-Z_{l}^{3}\right)+\frac{b_{1}}{2}\left(Z_{u}^{2}-Z_{l}^{2}\right)-\left(b_{1}+b_{2}\right)\left(Z_{u}-Z_{l}\right) \\ -\frac{b_{3}}{3}\left[\left(a_{1}-Z_{u}\right)^{3} J_{1}-\left(a_{1}-Z_{l}\right)^{3} K_{1}\right] \\ -\frac{b_{4}}{3}\left[\left(a_{2}-Z_{u}\right)^{3} J_{2}-\left(a_{2}-Z_{l}\right)^{3} K_{2}\right]\end{array}\right\}$

Burada,

$Z_{l}=\frac{h_{l}}{H}, Z_{u}=\frac{h_{u}}{H}$,

$J_{i}=\left\{\begin{array}{ll}1 & Z_{u} \leq a_{i} \\ 0 & Z_{u}>a_{i}\end{array} \quad i=1,2\right.$

$K_{i}=\left\{\begin{array}{ll}1 & Z_{l} \leq a_{i} \\ 0 & Z_{l}>a_{i}\end{array} \quad i=1,2\right.$

Tüm değişkenler daha önceki bölümlerde açıklanmıştır.

Model 4: Clark vd. (1991) tarafindan, Schlaegel'in ve Max ve Burkhart (1976) modellerinin daha iyi özelliklerini birleştiren karmaşık bir parçalı gövde çap1 modeli geliştirilmiştir. Bu model ağaç gövdesini dört farklı parçada incelemektedir.

(1) Dip kısım: Kütük ile $1.30 \mathrm{~m}$ arasındaki bölümü.

(2) Alt kısım: Gövdenin $1.30 \mathrm{~m}$ ile $5.30 \mathrm{~m}$. arasındaki bölümü.

(3) Orta kısım: Gövdenin 5.30 m ile toplam boyun \%40-70’i arasındaki bölüm

(4) Üst kısım: Toplam boyun \%40-70'inden ağacın uç kısmına kadar olan bölüm.

$\mathrm{Bu}$ model farklı ağaç türlerindeki çap tahminlerinde, gövdenin $1.30 \mathrm{~m}$ altındaki bölümünde varyasyonun \%90'dan fazlasını; $1.30 \mathrm{~m}$ ile $5.30 \mathrm{~m}$ arasındaki bölümünde \%97 ile \%99'unu; 5.30 m'nin üstündeki bölümlerde ise toplam varyasyonun \%93 ile \%99'unu açıklayabilmektedir. Clark vd. (1991) model formu aşağıdaki gibi ifade edilebilir.

$\mathrm{d}=\left\{\begin{array}{l}I_{S}\left[D^{2}\left(1+\frac{\left(b_{2}+b_{3} / D^{3}\right)\left((1-h / H)^{b_{1}}-(1-1.30 / H)^{b_{1}}\right)}{1-(1-1.30 / H)^{b_{1}}}\right]+\right. \\ I_{B}\left[D^{2}-\frac{\left(D^{2}-F^{2}\right)\left((1-1.30 / H)^{b_{4}}-(1-h / H)^{b_{4}}\right)}{(1-1.30 / H)^{b_{4}}-(1-5.30 / H)^{b_{4}}}\right]+ \\ I_{T}\left[F^{2}\left(b_{6}\left(\frac{h-5.30}{H-5.30}-1\right)^{2}+I_{M}\left(\frac{1-b_{6}}{b_{5}^{2}}\right)\left(b_{5}-\frac{h-5.30}{H-5.30}\right)^{2}\right)\right]\end{array}\right\}^{0.5}$

Burada,

$b_{1}, \quad b_{2}, \quad b_{3}=$ gövdenin $1.30 \mathrm{~m}$ altındaki kısmı için regresyon katsayılarını,

$b_{4}=$ gövdenin $1.30 \mathrm{~m}$ ile $5.30 \mathrm{~m}$ arasındaki kısmı için regresyon katsayılarını,

$b_{5}, \quad b_{6}=$ gövdenin $5.30 \mathrm{~m}$ üstündeki kısmı için regresyon katsayılarını, 
$F=5.30 \mathrm{~m}$ yükseklikteki kabuklu gövde çapını $(\mathrm{cm})$ ifade etmektedir.

Denklem (7) ve (9) için 5.30 m'deki çap değerinin bilinmesi gerekmektedir. Clark vd. (1991) tarafindan 5.30 m'deki çap değerini tahmin edebilen bir denklem geliştirilmiştir. Bu denklem aşağıdaki gibi ifade edilebilir. $\mathrm{Bu}$ denklemdeki $c_{i}$ model katsayılarıdır.

$F_{\text {dob5.3 }}=D\left(c_{1}+c_{2}\left(\frac{5.30}{H}\right)^{2}\right)$

Gövde çapı modeli için dört gösterge değişkeni, aşağıdaki gibi tanımlanmıştır.

$I_{S}=\left\{\begin{array}{ll}1 & h<1.30 \\ 0 & \text { aksi halde }\end{array}, I_{B}=\left\{\begin{array}{ll}1 & 1.30 \leq h<5.30 \\ 0 & \text { aksi halde }\end{array}\right.\right.$,

$I_{T}= \begin{cases}1 & h>5.30 \\ 0 & \text { aksi halde }\end{cases}$

$I_{M}= \begin{cases}1 & h<\left(5.30+b_{5}(H-5.30)\right) \\ 0 & \text { aksi halde }\end{cases}$

Diğer tüm değişkenler daha önceki bölümlerde açıklanmıştır.

Clark vd. (1991) tarafindan güney Appalachian yapraklı ve ibreli ağaç türleri için parçalı gövde çapı denklemleri geliştirilmiş ve üç katılma noktasına sahip parçalı polinom modellerle, gövde profilinin daha doğru bir şekilde modellendiğini ortaya konmuştur.

$V=k\left\{\begin{array}{l}I_{1} D^{2}\left[(1-G W)\left(U_{1}-L_{1}\right)+\frac{W\left(\left(1-L_{1} / H\right)^{b_{1}}\left(H-L_{1}\right)-\left(1-U_{1} / H\right)^{b_{1}}\left(H-U_{1}\right)\right)}{\left(b_{1}+1\right)}\right] \\ +I_{2} I_{3}\left[T\left(U_{2}-L_{2}\right)+\frac{Z\left(\left(1-L_{2} / H\right)^{\left.b_{4}\left(H-L_{2}\right)-\left(1-U_{2} / H\right)^{b_{4}}\left(H-U_{2}\right)\right)}\right.}{\left(b_{4}+1\right)}\right] \\ +I_{4} F^{2}\left[\begin{array}{l}b_{6}\left(U_{3}-L_{3}\right)-\frac{b_{6}\left(\left(U_{3}-5.30\right)^{2}-\left(L_{3}-5.30\right)^{2}\right)}{(H-5.30)} \\ +\frac{b_{6} / 3\left(\left(U_{3}-5.30\right)^{3}-\left(L_{3}-5.30\right)^{3}\right.}{(H-5.30)^{2}} \\ +\frac{I_{5}(1 / 3)\left(1-b_{6} / b_{5}^{2}\right)\left(b_{5}(H-5.30)-\left(L_{3}-5.30\right)\right)^{3}}{(H-5.30)^{2}} \\ -\frac{I_{6}(1 / 3)\left(1-b_{6} / b_{5}^{2}\right)\left(b_{5}(H-5.30)-\left(U_{3}-5.30\right)\right)^{3}}{(H-5.30)^{2}}\end{array}\right]\end{array}\right\}$

Burada,

$G=\left(1-\frac{1.30}{H}\right)^{b_{1}}, W=\left(b_{2}+b_{3} / D^{3}\right) /(1-G)$,

$x=(1-1.30 / H)^{b_{4}}, y=(1-5.30 / H)^{b_{4}}, T=D^{2}-Z X$,

$z=\left(D^{2}-F^{2}\right) /(x-y), L_{1}=\max (L, 0.30)$,

$L_{2}=\max (L, 1.30), L_{3}=\max (L, 5.30)$,

$U_{1}=\min (U, 1.30), U_{2}=\min (U, 5.30), U_{3}=\min (U, H)$,

$I_{1}=\left\{\begin{array}{ll}1 & L<1.30 \\ 0 & \text { aksi halde }\end{array}, \quad I_{2}=\left\{\begin{array}{ll}1 & L<5.30 \\ 0 & \text { aksi halde }\end{array} \quad I_{3}=\right.\right.$ $\begin{cases}1 & U>1.30 \\ 0 & \text { aksi halde }\end{cases}$

\{ aksi halde'

$I_{5}=\left\{\begin{array}{ll}1 & \left(L_{3}-5.30\right)<b_{5}(H-5.30) \\ 0 & \text { aksi halde }\end{array}\right.$, $I_{4}=\left\{\begin{array}{ll}1 & U>5.30 \\ 0 & \text { aksi halde }\end{array}\right.$,

$\left\{\begin{array}{ll}1 & \left(U_{3}-5.30\right)<b_{5}(H-5.30) \\ 0 & \text { aksi halde }\end{array}, k=0.0000785\right.$

Diğer tüm değişkenler daha önceki bölümlerde açıklanmıştır.

\section{Model performanslarının değerlendirilmesi}

Model performanslarını değerlendirmek amacıyla, ortalama hata (MD), tahminlerin standart hatası (SEE) ve Schlaegel (1981) tarafindan önerilen uyum indeksi (FI) ölçütleri kullanılmıştır. $\mathrm{Bu}$ değerlendirme kriterleri aşağıdaki gibi ifade edilebilmektedir.

$M D=\frac{\sum_{i=1}^{n}\left(Y_{i}-\hat{Y}_{i}\right)}{n}$
$S E E=\sqrt{\frac{\sum_{i=1}^{n}\left(Y_{i}-\hat{Y}_{i}\right)^{2}}{n-k}}$
$F I=1-\left[\frac{\sum_{i=1}^{n}\left(Y_{i}-\hat{Y}_{i}\right)^{2}}{\sum_{i=1}^{n}\left(Y_{i}-\bar{Y}\right)^{2}}\right]$

Burada,

$Y_{i}=i$. gözlem için ölçülen değeri,

$\hat{Y}_{i}=$ i. gözlem için tahmin edilen değeri,

$\bar{Y}=$ ölçülen değerlerin ortalamasını

$k=$ parametre sayısinı,

$n=$ veri setindeki gözlem sayısını ifade etmektedir.

Gövde çapı ve hacim tahminlerindeki hataları en aza indirgemek amacıyla, her iki denklem eşzamanlı olarak SAS paket programındaki PROC MODEL ile çözülmüştür (SAS Institute, 2002). Bu yaklaşımda genelleştirilmiş moment metodu (GMM), tam bilgi maksimum olabilirlik yöntemi (FIML) ve görünürde uyumsuz regresyon yöntemi (SUR) gibi parametre tahmin yöntemleri bulunmaktadır. Bu çalışmada, parametre tahmini için görünürde uyumsuz regresyon metodu (SUR) kullanılmıştır. Model parametreleri, gövde çapı ve gövde hacim denklemlerine paylaştırılmıştır. Bilindiği gibi, uyumlu gövde çapı modellerinde, gövde çapı modelinin herhangi iki nokta için integrali alınarak hacim denklemi elde edilebilmektedir. Böyle bir durumda, gövde çapı modeli ile hacim modeli için ortaya çıkacak hataların ilişkisiz olmasını beklemek gerçekçi olmayacaktır. Model sistemi içerisindeki gövde çapı modeli ile hacim modeli ilișkisiz göründüğü için SUR metodu kullanılmıştır, ancak modeller ilişkili hata yapısına sahiptir (Jiang vd., 2007). Bu nedenle, model geliştirme sürecinde ilişkili hata yapısı hesaba katıldığı durumlarda bile, modelin tahmin başarısı, ilişkili hata yapısından çok az etkilendiği için veri setindeki ilişkili hata yapısı SAS MODEL yaklaşımında dikkate alınmamıştır (Williams ve Reich, 1997; Kozak, 1997; Brooks vd., 2008).

\section{Bulgular ve tartışma}

Toros göknarı için test edilen modellere ilişkin parametre tahminleri, gövde çapı ve hacim denklemlerinin eş zamanlı olarak çözülmesiyle elde edilmiştir. Tüm parametreler $<0.0001$ önem düzeyinde anlamı bulunmuştur. Ticari gövde için genel uyum istatistikleri (MD, SEE ve FI), çalışma kapsamında test edilen tüm denklemler için hesaplanarak, Çizelge 3 'te verilmiştir. Sonuçlar, tüm gövde çapı modellerinin, çap tahminlerindeki varyasyonun \%98'inden fazlasını açıkladığını göstermiştir. Tahminlerin standart hatası (SEE) ise yaklaşık olarak 1.2-1.8 cm arasında değişmektedir. 
Çizelge 3. Toros göknarı için uyumlu gövde çapı ve hacim denklemleri için elde edilen uyum istatistikleri

\begin{tabular}{lccc}
\hline Modeller & MD & SEE & FI \\
\hline Kozak vd. (1969) & & & \\
\hline Gövde Çap1 (cm) & 0.2745 & 1.7701 & 0.9833 \\
Hacim (m $\left.{ }^{3}\right)$ & 0.0026 & 0.0116 & 0.9651 \\
\hline Demaerschalk (1972) & & & \\
\hline Gövde Çap1 (cm) & 0.1914 & 1.2912 & 0.9907 \\
Hacim (m $\left.{ }^{3}\right)$ & 0.00016 & 0.0086 & 0.9771 \\
\hline Max-Burkhart (1976) & & & \\
\hline Gövde Çap1 (cm) & 0.2370 & 1.7402 & 0.9841 \\
Hacim (m $\left.{ }^{3}\right)$ & 0.0020 & 0.0112 & 0.9668 \\
\hline Clark vd. (1991) & & & \\
\hline Gövde Çap1 $(\mathrm{cm})$ & 0.1740 & 1.2333 & 0.9916 \\
Hacim (m $\left.{ }^{3}\right)$ & 0.00006 & 0.0082 & 0.9795 \\
\hline
\end{tabular}

Gövde çapı modellerinin ticari ağaç gövdesinin farklı noktalarındaki tahmin başarısını değerlendirmek amacıyla farklı nispi boy $(h / H)$ sınıfları için tahmin performansları değerlendirilmiştir. $\mathrm{Bu}$ amaçla, veri seti 10 nispi boy sınıfına ayrılmıştır. Nispi boy sınıfları itibariyle modellerin çap ve hacim tahminlerindeki performanslarını değerlendirmek amaciyla, MD ve SEE değerleri her bir denklem için hesaplanmış ve çap değerlerine ilişkin sonuçlar Çizelge 4'de; hacim tahminleri için elde edilen sonuçlar ise Çizelge 5'te verilmiştir.

Clark vd. (1991) modelinin çap tahmin performansı incelendiğinde, SEE değerinin gövdenin alt kısımlarında nispeten daha düşük olduğu görülmektedir (Çizelge 4). Buna karşılık, Demaerschalk (1972) modeli için MD ve SEE değerlerinin, gövdenin alt bölümlerinde daha yüksek olduğu görülmektedir. Kozak (1969), Demaerschalk (1972) ve Max ve Burkhart (1976) tarafindan geliştirilen modellerin, çap tahminlerinde genel olarak toplam boyun $\% 10$ ile \%85 arasındaki kısımlarında başarılı sonuçlar verdiği görülürken, ağaç gövdesinin dip ve uç kısımlarında yapılan çap tahminlerinde ise nispeten daha başarısız olduğu söylenebilir. Max ve Burkhart (1976) ve Clark vd. (1991) tarafindan geliştirilen modeller, model geliştirme ve test verileriyle yapılan değerlendirmeler sonucunda Toros göknarı türü için gövdeni farklı bölümleri bakımından tutarlı performanslar göstermiştir. Demaerschalk (1972) ve Kozak vd. (1969) tarafindan geliştirilen modellerin MD değerlerinde yüksek varyasyonlar görülmektedir (Şekil 1). Genel olarak, model test verileri ile yapilan değerlendirmeler sonucunda elde edilen MD değerlerinin, Kozak vd. (1969) modeli için yüksek; Clark vd. (1991) modeli için düşük olduğu görülmektedir.

Toplam gövde hacmi tahminlerine ilişkin olarak test edilen modellerin uyum istatistikleri (MD, SEE ve FI)
Çizelge 3'te verilmiş̧ir. Çalışma kapsamında test edilen modellerden Kozak vd. (1969), Max ve Burkhart (1976), Demaerschalk (1972), ve Clark vd. (1991), Toros göknarı toplam gövde hacim tahminlerindeki varyasyonun sırasıyla, yaklaşık \%97, \%98, \%97 ve \%98'ni açıklayabilmektedir. Modeller, bu bakımdan önemli bir farklılık göstermemektedir.

Gövde çapı modellerinin hacim tahminleri için SEE değerlerinin 0.008 ile $0.012 \mathrm{~m}^{3}$ 'arasında değiştiği ve en düşük sonuçların Clark vd. (1991) ile elde edildiği görülmektedir. Çalışma kapsamında nispi boylar itibariyle hacim tahminleri de değerlendirilmiştir (Çizelge 5). Ortalama hata (MD) değerleri; Kozak vd. (1969) için 0.0010-0.0069 m³ , Demaerschalk (1972) için 0.0002-0.0030 $\mathrm{m}^{3}$, Max ve Burkhart (1976) için 0.0003-0.0037 $\mathrm{m}^{3}$ ve Clark vd. (1991) için 0.0000-0.0019 $\mathrm{m}^{3}$ arasında değişmektedir. Model test verileri itibariyle yapılan değerlendirme sonucunda, modellerin tüm gövde hacmi dışında, birçok gövde bölümü için düşük MD ve SEE değerleri ile başarılı tahminler ürettiği görülmüştür. Clark vd. (1991) tarafından geliştirilen model, gövde çapı tahminlerinde ve özellikle büyük çaplar için hacim tahminlerinde, diğer modellerden daha başarılı sonuçlar vermiştir. Bu özellik, uygulanabilirlik veya ekonomik açıdan önem arz etmektedir. Kozak vd. (1969) ve Max ve Burkhart (1976) tarafindan geliştirilen modeller, hacim tahminlerinde gövdenin ticari açıdan en önemli bölümü olan ana gövde kısmında (dipten toplam boyun yaklaşık \%40'ına kadar olan kısım), diğer modellere göre daha başarısız sonuçlar üretmiştir.

Kozak ve Smith (1993), birçok araştırmacının, MD veya SEE'yi kullanan tek bir sıralama sistemini kullandıklarını, sıralamalar toplamının ise nadiren kullanıldığını belirtmişlerdir. Gövde çapı modellerini sıralamanın bir başka yolu da MD ve SEE değerleri kullanarak, gövdenin farklı çap değerleri için elde edilen tahmin performansını sıralamaktır. Çizelge 6'nın 3-6 satırları bu şekilde elde edilmiş; her bir gövde çapı modeli, boy sınıfları itibariyle sıralanmıştır. Model performanslarının değerlendirilmesi, söz konusu bu yardımcı sıralama sistemleri ile daha başarılı bir şekilde yapılabilmektedir. Demaerschalk (1972) tarafından geliştirilen model, bu beş kategoride ikinci sırada yer almaktadir. Max ve Burkhart (1976) tarafindan geliştirilen model, yerden uca kadarki çap tahminlerinde ortalama hata (MD) itibariyle ikinci sırada yer almaktadır. Kozak vd. (1969) tarafindan geliştirilen model ise genel olarak dördüncü sırada yer almaktadır. $\mathrm{Bu}$ sonuçlar, Figueiredo-Filho vd. (1996) tarafindan elde edilen sonuçlarla benzerlik göstermektedir.

Çizelge 4. Çap tahminleri için farklı nispi boylar (RH) itibariyle elde edilen ortalama hata (MD) ve tahminlerin standart hatası (SEE) değerleri

\begin{tabular}{|c|c|c|c|c|c|c|c|c|c|}
\hline \multirow{2}{*}{ RH } & \multirow{2}{*}{$\mathrm{N}$} & \multicolumn{2}{|c|}{ Kozak vd. (1969) } & \multicolumn{2}{|c|}{ Demaerschalk (1972) } & \multicolumn{2}{|c|}{ Max ve Burkhart (1976) } & \multicolumn{2}{|c|}{ Clark vd. (1991) } \\
\hline & & $\mathrm{MD}(\mathrm{cm})$ & SEE $(\mathrm{cm})$ & $\mathrm{MD}(\mathrm{cm})$ & SEE $(\mathrm{cm})$ & $\mathrm{MD}(\mathrm{cm})$ & SEE $(\mathrm{cm})$ & $\mathrm{MD}(\mathrm{cm})$ & $\mathrm{SEE}(\mathrm{cm})$ \\
\hline $0.0-0.1$ & 281 & 0.0324 & 1.3396 & 0.5487 & 1.2103 & 0.2872 & 1.3386 & 0.0013 & 0.7858 \\
\hline $0.1-0.2$ & 255 & 0.6141 & 1.6620 & -0.3272 & 0.9396 & 0.0893 & 1.4235 & -0.1351 & 0.8886 \\
\hline $0.2-0.3$ & 238 & 0.4536 & 1.9739 & -0.2741 & 1.2480 & 0.1584 & 1.8723 & 0.0622 & 1.3007 \\
\hline $0.3-0.4$ & 251 & 0.2193 & 1.9430 & -0.1382 & 1.2884 & 0.1352 & 1.9264 & 0.1599 & 1.2485 \\
\hline $0.4-0.5$ & 261 & 0.1595 & 2.1305 & -0.1216 & 1.5221 & 0.2522 & 2.1804 & 0.1536 & 1.4552 \\
\hline $0.5-0.6$ & 236 & 0.1138 & 1.8801 & 0.0494 & 1.3173 & 0.3245 & 1.9740 & 0.3409 & 1.4149 \\
\hline $0.6-0.7$ & 247 & 0.0035 & 1.8194 & 0.2938 & 1.4115 & 0.2278 & 1.9087 & 0.4817 & 1.4205 \\
\hline $0.7-0.8$ & 250 & 0.2525 & 1.8034 & 0.3738 & 1.3803 & 0.3395 & 1.8541 & 0.3493 & 1.3932 \\
\hline $0.8-0.9$ & 253 & 0.4532 & 1.7045 & 0.5896 & 1.3367 & 0.3064 & 1.6413 & 0.1891 & 1.3223 \\
\hline $0.9-1.0$ & 234 & 0.4786 & 1.3724 & 0.9134 & 1.2382 & 0.2466 & 1.2567 & 0.1724 & 1.0868 \\
\hline Tümü & 2506 & 0.2745 & 1.7701 & 0.1914 & 1.2912 & 0.2370 & 1.7402 & 0.1740 & 1.2333 \\
\hline & & FI & 0.9836 & FI & 0.9907 & FI & 0.9841 & FI & 0.9916 \\
\hline
\end{tabular}


Not: MD ve SEE için hesaplanan “Tümü” genel ortalama ile elde edilmiştir.

Çizelge 5. Hacim tahminleri için farklı nispi boylar (RH) itibariyle elde edilen ortalama hata (MD) ve tahminlerin standart hatası (SEE) değerleri

\begin{tabular}{|c|c|c|c|c|c|c|c|c|c|}
\hline \multirow{2}{*}{ RH } & \multirow{2}{*}{$\mathrm{n}$} & \multicolumn{2}{|c|}{ Kozak vd. (1969) } & \multicolumn{2}{|c|}{ Demaerschalk (1972) } & \multicolumn{2}{|c|}{ Max ve Burkhart (1976) } & \multicolumn{2}{|c|}{ Clark vd. (1991) } \\
\hline & & $\operatorname{MD}\left(\mathrm{m}^{3}\right)$ & $\operatorname{SEE}\left(\mathrm{m}^{3}\right)$ & $\operatorname{MD}\left(\mathrm{m}^{3}\right)$ & $\operatorname{SEE}\left(\mathrm{m}^{3}\right)$ & $\operatorname{MD}\left(\mathrm{m}^{3}\right)$ & $\operatorname{SEE}\left(\mathrm{m}^{3}\right)$ & $\operatorname{MD}\left(\mathrm{m}^{3}\right)$ & $\operatorname{SEE}\left(\mathrm{m}^{3}\right)$ \\
\hline $0.0-0.1$ & 281 & 0.0030 & 0.0221 & -0.0030 & 0.0205 & 0.0018 & 0.0218 & 0.0000 & 0.0198 \\
\hline $0.1-0.2$ & 255 & 0.0064 & 0.0155 & 0.0028 & 0.0074 & 0.0037 & 0.0131 & -0.0019 & 0.0075 \\
\hline $0.2-0.3$ & 238 & 0.0044 & 0.0138 & 0.0019 & 0.0083 & 0.0031 & 0.0128 & -0.0004 & 0.0080 \\
\hline $0.3-0.4$ & 251 & 0.0028 & 0.0119 & 0.0011 & 0.0069 & 0.0027 & 0.0118 & 0.0004 & 0.0064 \\
\hline $0.4-0.5$ & 261 & 0.0023 & 0.0107 & 0.0010 & 0.0069 & 0.0028 & 0.0112 & 0.0003 & 0.0064 \\
\hline $0.5-0.6$ & 236 & 0.0015 & 0.0076 & 0.0001 & 0.0051 & 0.0023 & 0.0083 & 0.0010 & 0.0050 \\
\hline $0.6-0.7$ & 247 & 0.0011 & 0.0060 & -0.0004 & 0.0040 & 0.0017 & 0.0065 & 0.0009 & 0.0040 \\
\hline $0.7-0.8$ & 250 & 0.0013 & 0.0047 & -0.0006 & 0.0029 & 0.0014 & 0.0048 & 0.0004 & 0.0030 \\
\hline $0.8-0.9$ & 253 & 0.0010 & 0.0027 & -0.0007 & 0.0017 & 0.0007 & 0.0026 & 0.0001 & 0.0018 \\
\hline $0.9-1.0$ & 234 & 0.0004 & 0.0011 & -0.0002 & 0.0007 & 0.0003 & 0.0009 & -0.0001 & 0.0004 \\
\hline Tümü & 2506 & 0.0024 & 0.0116 & 0.00015 & 0.0086 & 0.0020 & 0.0112 & 0.00006 & 0.0082 \\
\hline & & FI & 0.9651 & FI & 0.9771 & FI & 0.9668 & FI & 0.9795 \\
\hline
\end{tabular}

Not: MD ve SEE için hesaplanan "Tümü” genel ortalama ile elde edilmiștir.

Çizelge 6. Gövde çapı modellerinin sıra toplamlarına (parantez içinde) dayalı sıralaması

\begin{tabular}{|c|c|c|c|c|}
\hline \multirow[b]{2}{*}{ Açıklama } & \multicolumn{4}{|c|}{ Modeller } \\
\hline & $\begin{array}{c}\text { Kozak vd. } \\
(1969)\end{array}$ & $\begin{array}{c}\text { Demaerschalk } \\
(1972)\end{array}$ & $\begin{array}{c}\text { Max ve Burkhart } \\
(1976)\end{array}$ & $\begin{array}{c}\text { Clark vd. } \\
(1991)\end{array}$ \\
\hline Çap $(d)$ ve hacim $(V)$ için genel SEE & $8(4)$ & $4(2)$ & $6(3)$ & $2(1)$ \\
\hline Çap $(d)$ ve hacim $(V)$ genel MD & $8(4)$ & $4(2)$ & $6(3)$ & $2(1)$ \\
\hline Farklı nispi boy değerleri için SEE $(d)$ & $37(4)$ & $16(2)$ & $34(3)$ & $13(1)$ \\
\hline Farklı nispi boy değerleri için MD (d) & $28(4)$ & $26(3)$ & $24(2)$ & $22(1)$ \\
\hline Farklı nispi boy değerleri için SEE $(V)$ & $36(4)$ & $17(2)$ & $34(3)$ & $13(1)$ \\
\hline Farklı nispi boy değerleri için MD ( $V$ ) & $36(4)$ & $20(2)$ & $32(3)$ & $12(1)$ \\
\hline Toplam & $153(24)$ & $87(13)$ & $136(17)$ & $64(6)$ \\
\hline
\end{tabular}

Son olarak, dört gövde çapı modeli, tüm veri seti (model geliştirme ve model test verilerinin birleştirilmesi) kullanılarak yeniden değerlendirilmiş ve elde edilen parametre tahminleri Çizelge 7'de gösterilmiştir.

Modellerin çap ve hacim tahminlerindeki performansları grafiksel olarak da gösterilmiştir. Şekil 2 ve Şekil 3, sırasıyla dört model için nispi boy $(\mathrm{RH})$ sınıfları itibariyle çap ve hacim tahminlerindeki hataların dağılışını göstermektedir.

Çizelge 7. Toros göknarı için uyumlu gövde çapı ve hacim denklemleri için elde edilen parametre tahminleri

\begin{tabular}{ccccc}
\hline Parametre & $\begin{array}{c}\text { Kozak vd. } \\
(1969)\end{array}$ & $\begin{array}{c}\text { Demaerschalk } \\
(1972)\end{array}$ & $\begin{array}{c}\text { Max ve } \\
\text { Burkhart } \\
(1976)\end{array}$ & $\begin{array}{c}\text { Clark vd. } \\
(1991)\end{array}$ \\
\hline$b_{1}$ & -2.0466 & 0.2110 & -2.3621 & 5.2524 \\
$b_{2}$ & 0.8733 & 0.9435 & 1.0462 & 0.1783 \\
$b_{3}$ & & 0.8148 & -0.3624 & 1218.746 \\
$b_{4}$ & & -0.8895 & 11.3651 & 2.3669 \\
$b_{5}$ & & & & 0.9861 \\
$b_{6}$ & & & & 10.3318 \\
$a_{1}$ & & & 0.7350 & \\
$a_{2}$ & & & 0.1152 & \\
\hline
\end{tabular}

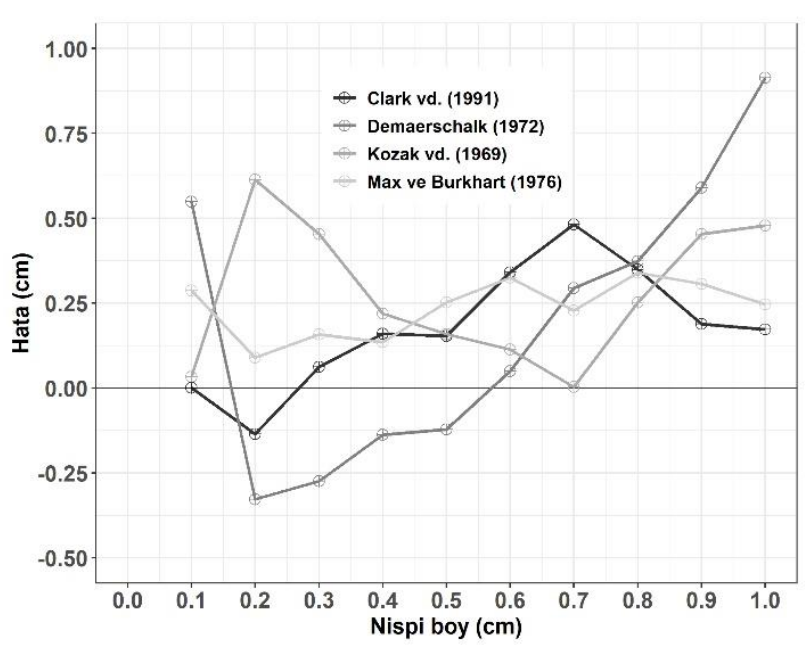

Şekil 2. Toros göknarı çap tahminlerinin nispi boy (RH) sınıfları itibariyle MD dağılımı 


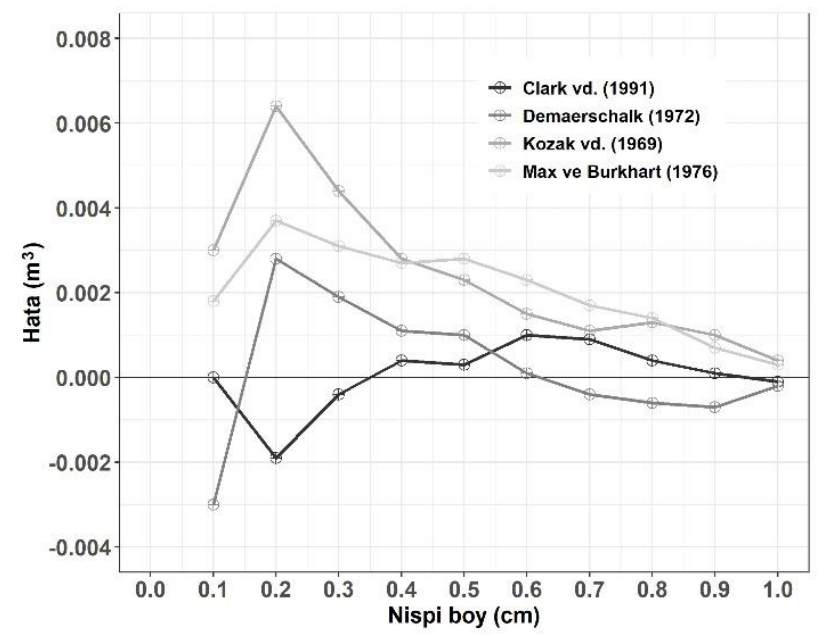

Şekil 3. Toros göknarı hacim tahminlerinin nispi boy (RH) sınıfları itibariyle MD dağılımı

\section{Sonuç ve öneriler}

$\mathrm{Bu}$ çalışmada, bir gövde çapı modelinin seçiminde dikkat edilmesi gereken pratik ormancılık uygulamaları ve istatistiki değerlendirme ölçütleri, iki basit gövde çapı modeli (Kozak vd., 1969 ve Demaerschalk, 1972) ve iki parçalı gövde çapı modeli (Max ve Burkhart, 1976 ve Clark vd., 1991) kullanılarak karşılaştırılmıştır. Sayısal tutarlılığı sağlamak ve gövde çapı ve hacim tahminlerindeki hataları en aza indirmek amacıyla, her bir gövde çapı ve hacim denklemine ait parametre tahminleri eş zamanlı olarak gerçekleştirilmiştir. Yapılan değerlendirmeler sonucunda, Clark vd. (1991) tarafından geliştirilen modelin, gövde profilinin modellenmesi ve gövde hacminin tahmininde en iyi performansı gösterdiği belirlenmiştir. Önerilen gövde çapı modeli, ağaç gövdesi üzerindeki herhangi iki çap veya iki boy değeri arasındaki gövde hacmini tahmin etmek için kullanılabilir olup, aynı ağaçtaki farklı ticari ürünlerin hacminin hesaplanmasında, yine bu denklemlerden faydalanılabilir. Bu model, gövde çapı ve hacim tahminleri için, bağımsız değişken olarak, göğüs çapı ve toplam ağaç boyun yanında, 5.30 m'deki çap değerine de ihtiyaç duymaktadır. Ancak, ülkemizdeki orman envanteri uygulamalarında, dikili ağaçlarda bu yükseklikteki çap değeri ölçülmemektedir. Üstelik sık meşcerelerdeki tüm ağaçlarda bu çap değerinin ölçülmesi neredeyse mümkün olamamaktadır. Orman envanteri maliyetleri de düşünüldüğünde, göğüs çapı ve ağaç boyuna ilave olarak her ağacın $5.30 \mathrm{~m}$ yüksekliğindeki çap değerinin de ölçümü maliyetleri önemli ölçüde arttıracaktır. Clark vd. (1991), bu çap değerinin ölçülemediği durumlarda, 5.30 m'deki çap değerinin tahmin edilebilmesi için bir denklem (8) önermiştir. Diğer yandan, Max ve Burkhart (1976) ve Demaerschalk (1972) tarafindan geliştirilen modeller de çap ve hacim tahmininde, genel uyum istatistikleri (MD, SEE ve FI) dikkate alındığında, tüm ağaç ve seksiyonel tahmin performansı açısından tutarlı sonuçlar ortaya koymuştur.

Kozak ve Smith (1993) tarafindan gövde çapı modelinin seçiminde pratik ormancılık uygulamaları ve istatistiki ölçütler açısından yapılan değerlendirmeler göz önüne alındığında, Toros göknarı meşcerelerinin hacim ve gövde çapı tahminleri için Demaerschalk (1972) ve Max ve
Burkhart (1976) tarafından geliştirilen modellerden birinin tercih edilmesi daha uygun olacaktır. Bu modeller, Clark vd. (1991) modeline göre gerek parametre tahminlerinin daha kolay olması ve gerekse uygulama kolaylığı açısından öne çıkmaktadır. Ancak, bu modeller arasında Max ve Burkhart (1976) tarafından geliştirilen modelin kullanılmasının daha uygun olacağı değerlendirilmiştir. Çünkü bu model, dünyanın pek çok yöresinde pek çok ağaç türü için test edilmiş; gövde çapı ve hacim tahminleri açısından başarılı sonuçlar üretmiş̧ir. Model, gövde çapı ve hacim tahminleri için bağımsız değişken olarak sadece göğüs çapı ve ağaç boyuna ihtiyaç duymaktadır. Bununla birlikte, daha başarılı hacim tahminlerine ihtiyaç duyulan durumlarda ve ağaçların $5.30 \mathrm{~m}$ yüksekliğindeki çap değerlerinin elde edilmesinde bir sıkıntı yok ise, Clark vd. (1991) tarafından geliştirilen gövde çapı modeli tercih edilebilir.

\section{Kaynaklar}

Alkan, O., Ozçelik, R., Alkan, H. 2019. Development of regional stem taper models for some important tree species of Turkey: Case study of Bucak. Turkish Journal of Forestry, 20(4): 333340.

Bailey, R.L., 1995. Upper stem volumes from stem analysis data: An overlapping bolts method. Canadian Journal of Forest Research, 25(1):170-173.

Bi, H., 2000. Trigonometric variable-form taper equations for Australian eucalypts. Forest Science, 46(3):397-409.

Biging, G.S., 1984. Taper equations for second-growth mixed conifers of Northern California. Forest Science, 30(4): 11031117.

Brooks, J.R., Jiang, L., Ozçelik, R., 2008. Compatible stem volume and taper equations for Brutian pine, Cedar of Lebanon, and Cilicica fir in Turkey. Forest Ecology and Management, 256(12): $147-151$

Cao, Q.V., Burkhart, H.E., Max, T.A., 1980. Evaluation of two methods for cubic-volume prediction of loblolly pine to any merchantable limit. Forest Science, 26(1), 71-80.

Clark, III, A., Souter, R.A., Schlaegel, B.E., 1991. Stem profile equations for southern tree species. USDA For. Serv. Res. Pap. SE-282.

Coble, D.W., Hilpp, K., 2006. Compatible cubic-foot stem volume and upper-stem diameter equations for semi-intensive plantation grown loblolly pine trees in East Texas. Southern Journal of Applied Forestry, 30(3): 132-141.

Demaerschalk, J.P., 1972. Converting volume equations to compatible taper equations. Forest Science, 18(3):241-245.

Demaerschalk, J.P., Kozak, A., 1977. The whole-bole system: A conditioned dual-equation system for precise prediction of tree profiles. Canadian Journal of Forest Research, 7(3):488-497.

Eker, M., Poudel, K.P., Özçelik, R., 2017. Aboveground biomass equations for small trees of brutian pine in Turkey to facilitate harvesting and management. Forests, 8(12): 477.

Fang, Z., Borders, B.E., Bailey, R.L., 2000. Compatible volumetaper models for loblolly and slash pine based on a system with segmented-stem form factors. Forest Science, 46(1):1-12.

Figueiredo-Filho, A., Borders, B.E., Hitch, K.L., 1996. Taper equations for Pinus taeda plantations in Southern Brazil. Forest Ecology and Management, 83(1-2):39-46.

Hilt, D.E., 1980. Taper-based system for estimating stem volume of upland oaks. USDA For. Serv. Res. Pap. NE-458,12 p.

Hussain, A., Shahzad, M.K., He, P., Jiang, L., 2020. Stem taper equations for three major conifer species of Northeast China. Scandinavian Journal of Forest Research, 35(8): 562576.

Hussain, A., Shahzad, M.K., Burkhart, H.E., Jiang, L., 2021. Stem taper functions for white birch (Betula platyphylla) and costata birch (Betula costata) in the Xiaoxing'an Mountains, northeast China. Forestry: An International Journal of Forest Research. 
Jiang, L., Brooks, J.R., Wang, J., 2005. Compatible taper and volume equations for yellow-poplar in West Virginia. Forest ecology and management, 213(1-3): 399-409.

Jiang, L., Brooks, J.R., Hobbs, G.R., 2007. Using crown ratio in yellow-poplar compatible taper and volume equations. Northern Journal of Applied Forestry, 24(4): 271275.

Jordan, L., Berenhaut, K., Souter, R., Daniels, R.F., 2005. Parsimonious and completely compatible taper, total, and merchantable volume models. Forest science, 51(6):578-584.

Kozak, A., 2004. My last words on taper equations. The Forestry Chronicle, 80(4):507-515.

Kozak, A., 1988. A variable-exponent taper equation. Canadian Journal of Forest Research, 18(11): 1363-1368.

Kozak, A. 1997. Effects of multicollinearity and autocorrelation on the variable-exponent taper functions. Canadian Journal of Forest Research, 27(5): 619-629.

Kozak, A., Munro, D.D., Smith, J.H.G., 1969. Taper functions and their application in forest inventory. The Forestry Chronicle, 45(4): 278-283.

Kozak, A., Smith, J.H.G., 1993. Standards for evaluating taper estimating systems. The Forestry Chronicle, 69(4):438-444.

Martin, A.J., 1981. Taper and volume equations for selected Appalachian hardwood species. USDA For. Serv. Res. Pap. NE-490.

Max, T.A., Burkhart, H.E., 1976. Segmented polynomial regression applied to taper equations. Forest Science, 22(3): 283-289.

McTague, J.P., Bailey, R.L., 1987. Simultaneous total and merchantable volume equations and a compatible taper function for loblolly pine. Canadian Journal of Forest Research, 17(1): 87-92.

McTague, J.P., Weiskittel, A., 2021. Evolution, history, and use of stem taper equations: a review of their development, application, and implementation. Canadian Journal of Forest Research, 51(2):210-235.

Newnham, R.M., 1988. A variable form taper function. Information Report PI-X-83. Forestry, Canada, p. 33.

Newnham, R.M., 1992. Variable-form taper functions for four Alberta tree species. Canadian Journal of Forest Research, 22(2): 210-223.

OGM, 2006. Orman Kaynakları. Orman Genel Müdürlüğü, Ankara, $159 \mathrm{~s}$.
Ormerod, D.W., 1986. The diameter-point method for tree taper description. Canadian Journal of Forest Research, 16(3): 484490.

Ormerod, D.W., 1973. A simple bole model. The Forestry Chronicle, 49(3): 136-138.

Özçelik, R., Crecente-Campo, F., 2016. Stem taper equations for estimating merchantable volume of Lebanon cedar trees in the Taurus Mountains, Southern Turkey. Forest Science, 62(1):78.

Özçelik, R., Alkan, H., 2012. Okaliptüs ağaçlandırmaları için uyumlu gövde çap1 ve gövde hacim modellerinin geliştirilmesi. Kahramanmaraș Sütçüimam Üniversitesi Doğa Bilimleri Dergisi, 15:247-254.

SAS Institute Inc., 2002. SAS/ETS User's Guide, Version 9.0, SAS Institute Inc., Cary, NC.

Schlaegel, B.E., 1981. Testing, reporting, and using biomass estimation models. Southern Forest Biomass Workshop, 11-12 June, Georgetown, South Carolina, USA, pp. 95-112.

Shahzad, M.K., Hussain, A., Jiang, L., 2020. A model form for stem taper and volume estimates of Asian white birch (Betula platyphylla): a major commercial tree species of Northeast China. Canadian Journal of Forest Research, 50(3): 274-286.

Shahzad, M.K., Hussain, A., Burkhart, H.E., Li, F., Jiang, L., 2021. Stem taper functions for Betula platyphylla in the Daxing'an Mountains, northeast China. Journal of Forestry Research, 32: 529-541.

Sharma, M., Oderwald, R.G., 2001. Dimensionally compatible volume and taper equations. Canadian Journal of Forest Research, 31(5): 797-803.

Sharma, M., Parton, J., 2009. Modeling stand density effects on taper for jack pine and black spruce plantations using dimensional analysis. Forest science, 55(3): 268-282.

Thomas, C.E., Parresol, B.R., 1991. Simple, flexible, trigonometric taper equations. Canadian Journal of Forest Research, 21(7): 1132-1137.

Williams, M.S., Reich, R.M., 1997. Exploring the error structure of taper equations. Forest science, 43(3): 378-386.

Zakrzewski, W.T., MacFarlane, D.W., 2006. Regional stem profile model for cross-border comparisons of harvested red pine (Pinus resinosa Ait.) in Ontario and Michigan. Forest Science, 52(4): 468-475. 